\title{
Lexis
}

Journal in English Lexicology

17 | 2021

Humor, creativity and lexical creation

\section{Deviance in children's literature as a form of creativity with a humorous effect}

\section{Cécile Poix}

\section{(2) OpenEdition}

1 Journals

\section{Electronic version}

URL: https://journals.openedition.org/lexis/5253

DOI: $10.4000 /$ lexis.5253

ISSN: 1951-6215

\section{Publisher}

Université Jean Moulin - Lyon 3

\section{Electronic reference}

Cécile Poix, "Deviance in children's literature as a form of creativity with a humorous effect", Lexis [Online], 17 | 2021, Online since 15 August 2021, connection on 20 August 2021. URL: http:// journals.openedition.org/lexis/5253 ; DOl: https://doi.org/10.4000/lexis.5253

This text was automatically generated on 20 August 2021.

\section{(c) (i) (9)}

Lexis is licensed under a Creative Commons Attribution-NonCommercial-NoDerivatives 4.0 International License. 


\title{
Deviance in children's literature as a form of creativity with a humorous effect
}

\author{
Cécile Poix
}

\section{Introduction}

1 It is not unusual to find idiosyncratic utterances in children's literature. A word, a phrase, its spelling, or the typographic transcription of its pronunciation can deviate from the norm. The quirk could easily have been avoided by using several possible utterances. However, the writer deliberately deforms language to catch the attention of the reader, often to produce a humorous effect.

This article reviews the concept of deviance and the extent to which it can be linked to humour in the context of children's literature.

2 There is no doubt that distorting language on purpose is an artistic activity on the part of the writer. According to Crystal [2002: 395], "a deviant or strange use of language may be highly effective and widely appreciated - as in an art form". Schmid [2020: 74-81] describes several forces affecting language usage. For the present study of linguistic idiosyncrasy (i.e. a distorted use of the linguistic medium), I pay particular attention to extravagance, expressivity, foregrounding and salience. The notion of salience encompasses unexpected, unconventional utterances. If linguistic deviance in books can be seen as a form of creativity, a playful activity for the writer, the perlocutionary effect on the reader can vary and does not necessarily trigger humour.

3 For the author's playful intention to be perceived by the reader, the utterance must stand out and its incongruity must be resolved. Thus, deviance can be seen as a continuum, where at one end of the spectrum, the perception of mirth is easily achieved, while at the other end the deviant utterance remains incongruous, ambiguous or indeed nonsensical. This article reviews various considerations on deviance at the lexical level and the potentiality of humour: Crystal's [1990] normal 
abnormality of "linguistic strangeness"; how far language can be bent and still understood, described as "language on the verge" (Katz [2018]); and the "semantic void" (Lecercle [1994]) of nonsense, a well-established genre in children's literature.

4 To analyse lexical creative deviance, I compiled a corpus of children's books (CHILL) ${ }^{1}$. The English section of the corpus (CHILL_EN, over 740,000 words) contains eleven children's classics written in British English during the nineteenth and twentieth centuries. From this corpus, I identified unknown forms using an exclusion list ${ }^{2}$ of more than 58,000 words. To identify the unattested forms in my corpus with the exclusion list, I used a hashing function script that included frequencies. The unknown word list once cleared of attested lexemes [OED3] ${ }^{3}$ and noise (mostly due to hyphenation, punctuation marks and spelling) - comprises around 1,500 occasionalisms.

5 The last section of this article reviews unusual humorous occurrences where the linguistic form conflicts with predictive models. They are analysed as schemes (playing with word forms), tropes (playing with word meanings) and the violation of strong collocations.

\section{Salience in expressive language}

6 Expressive language is the use of language that aims at drawing the attention of the reader/listener to the linguistic medium itself, generally by using unexpected and unconventional utterances (i.e. salience).

7 Under poetic licence, literary writers are free to depart from linguistic norms. As Crystal [2002: 412] states, "authors are free to circle above the language, to swoop down and take from it whatever they wish." Playing with the linguistic medium and constrained writing techniques have given rise to exceptional works ${ }^{4}$. Sometimes, playing with words is also used to demonstrate the importance of the norm it violates. The following example illustrates the importance of punctuation to avoid lexical ambiguity:

(1) James while John had had had had had had had had had had had a better effect on the teacher.

8 In (1) the sentence depends on punctuation, highlighting the importance of the prosodic system for meaning, and thus, the sentence must be written and read as such: "James, while John had had 'had had', had had 'had', 'had had' had had a better effect on the teacher."

Such an extreme example of idiosyncratic utterance is unlikely to be produced in spontaneous face-to-face speech. Indeed, language can also be used in what Schmid [2020:75] presents as "elaborately planned and reflected, diligently crafted" utterances.

9 Schmid [2020:74] describes forces affecting the usage of language, which are "conceived as factors that motivate and modulate [speech] activities and affect how cognitive and social processes unfold". Schmid adopts Keller's maxims of action to analyse these forces. Our study is not concerned with maxims such as economy ("do not make unnecessary efforts" (Keller [2014:140, 142])) or communicative efficiency ("talk in such a way that you are understood", "talk in such a way that you are most likely to reach your communicative aims" (Keller [2014: 135])). 
The forces that best describe our subject matter are "extravagance, expressivity, foregrounding and salience" which Schmid [2020: 78] explains as follows:

In my view, the notion of extravagance highlights a more or less conscious and deliberate attitude on the part of the speaker during language production. In contrast, the notion of expressivity brings the linguistic forms themselves into focus. Expressive language can be the result of usage activities driven by extravagance. What I have in mind corresponds to the following maxims suggested by Keller (2014):

- Talk in such a way that people notice you (Keller [2014: 139]).

- Talk in an amusing and funny way (Keller [2014: 139]).

This indicates that extravagance shows in linguistic originality and creativity (Ishiyama 2014) and therefore contributes to dynamism and change, instead of persistence. It is mainly motivated by the goal of attracting attention to what is said and how it is said (Haspelmath 1999), and is thus related to Jakobson's (1960) poetic function of language.

11 Extravagance is the attitude of the speaker/writer who wants to be noticed, to amuse in a funny way. The extravagant writer uses expressive language to bring the linguistic forms into focus. According to Schmid [2020: 79],

the foregrounding potential inherent in expressive language is entrenched and conventionalized; in contrast, creative utterances motivated by extravagance tend to rely on noticeable deviations from what is entrenched and conventionalized. Thus, creativity is linked to deviance.

Schmid [2020: 78-79] describes various types of salience which are all relevant to the study of deviance in children's literature, namely salience by novelty, salience for its attention-getting potential and salience by surprisal.

Coining new words (salience by novelty) is quite usual in children's literature and can potentially be linked to humour. In CHILL_EN, Dahl is by far the most neophile author with $27.7 \%$ of all occasionalisms, most of which are overly conspicuous (e.g. hipswitch, squifflerotter, grinksludger, etc.). This explains why most of the examples in the present article are drawn from his novel The BFG. In literature, coinages, termed occasionalisms (Poix [2018]), follow the rules of word-formation. However, authors can also introduce new morphemes (with or without a gloss) which can be further affixed or compounded (e.g. whiffling, whiffling about, whiffling off, whoppsy-whiffling, wopsey whiffling, swishwiffling, all coined by Dahl). Such ex-nihilo creations are not restricted to one author or one subgenre. Occasionally they are capitalised (e.g. Were-worms by Tolkien, Byanplats by Pullman, Bapree-bap by Kipling, Quidditch by J.K. Rowling). Though this is not always the case (e.g. mithril by Tolkien, landloper by Pullman, gattling by Stevenson, etc.). Identifying salience by novelty of such inconspicuous coinages thus relies on the lexical knowledge of a reader. Thus, it is likely that a child reader may not even realise the creative and playful intention of an author.

14 Schmid [2020:79]. also defines salient utterances because of their attention-getting potential such as "interjections, strong language, exclamations, cleft sentences, more or less conventional metaphorical or metonymic language", etc. In children's literature strong offensive language is taboo. However, other types of expressive linguistic utterances can be used as "attention-seeking devices" (ASDs). An utterance can also belong to salience by novelty and draw the attention of the reader. As such, lengthy occasionalisms will automatically stand out as ASDs (e.g. scrumdiddlyumptious, crockadowndillies, or rhinostossterisses, coined by Dahl). Onomatopoeic interjections can also draw the attention of a reader. For instance, the oddity of the impossible cry of 
Carroll's gryphon "Hjckrrh", lacking an epenthetic vowel, violates the morphophonetic constraint and stands out. However, getting the attention of the reader does not necessarily lead to humour. When the oddity encrypts something that a reader must decipher, it then becomes entertaining. As such, Rowling's mirror writing "Erised stra ehru oyt ube cafru oyt on wohsi" 5 is ludic wordplay.

Schmid [2020: 78] also describes salience by surprisal where the linguistic form conflicts with predictive models:

Salient utterances of this type are indeed licensed by conventionalized utterance types, but they deviate in one way or another from what one would expect in the present co-text and context. [...] Violating a strong collocation or semantic prosody, [...] can thereby produce humorous, ironic, or sarcastic effects.

In CHILL_EN, $46.2 \%$ of all occasionalisms result from word-deformation processes. They vary in types, such as the alteration of an affix (carpentering < carpentry by Dickens), the reduplication of letters to emphasize a stretched sound sequence (my precioussss by Tolkien), the violation of grammatical rules (curiouser by Lewis, most bare-facedest by Dickens), etc.

Deviating from lexical, phonological, grammatical or syntactical conventions can easily lead to humour, since the incongruity can easily be resolved. When linguistic creativity reflects the playful impulse of the writer and his/her intention to surprise the reader with something unexpected and incongruous, humour is achieved once the humorous utterance is identified and unravelled.

To understand what triggers humour, one can consider Attardo's definition of puns [2018: 99]:

Puns have a built-in incongruity: a string activates two unrelated meanings (scripts); by its very presence, the ambiguity between the two activated meanings generates an incongruity (i.e. the presence of two unrelated meanings in the same text string. However, as I pointed out already in Attardo (1994), puns do not consist of incongruity alone but must have a resolution aspect as well, or otherwise they would be indistinguishable from mere incongruous or ambiguous statements.

Our study is not restricted to puns, but decrypting deviance follows the same type of resolution. The hypothesis is that, in order to achieve humour through linguistic deviance, the incongruity needs to be resolved. A full resolution is achieved when the original incongruity is no longer incongruous. Dahl's sentence "your spelling is atroshus" is humorous if a reader knows the adjective is misspelt. A partial resolution is also possible when the original incongruity becomes less incongruous. In Dahl's novel, giants gobble live human beings - aptly renamed "human beans") - once referred to as "half-baked beans". The association of "human beans" and "baked-beans" is easily made, though the utterance remains partly nonsensical. However, Dahl's full sentence is more challenging: "What is your flushbunking rotsome half-baked beans doing in our country?" Further levels of deviance can be identified here: the substitution of an affix (rotsome < rotting) and the euphemistic coinage to hide the f-word. Unlike a linguist, an average child reader is unlikely to linger on this deviant utterance to unravel its incongruity.

20 In children's literature, the resolution of wordplay depends on the linguistic ability of the child, potentially with assistance provided by an adult co-reader. To understand the extent of deviance that can be found in children's books, it is useful to review the variety of incongruities that linguistic deviance can produce. 


\section{Incongruous language}

Crystal [1990: 13] states that "linguistic strangeness is, in fact, a perfectly normal, everyday occurrence". Crystal [1990:14] analyses strangeness encountered in literary and in general language and makes the following statement:

In order to make the hypothesis interesting, I will assert it in its strongest possible form: that it is normal to be strange, as regards the use of language; that it is normal linguistic behaviour in most linguistic situations to depart from what is conceived of as a norm for that context. And before the evidence, some definitions. By "norm" here I mean only traditional, majority usage, intuitively appreciated and potentially quantifiable. And by strangeness I mean some untraditional, minority usage, again intuitively appreciated and potentially quantifiable.

Crystal underlines that strangeness is distinct from the specific use of distinctive variety or register that people use some of the time. Instead, it is defined as being "permanently available to all members of the speech community, who find themselves regularly responding to it (a passive awareness), with many of them regularly making active use of it in their speech" [1990: 14]. From this assertion, one can suppose that linguistic strangeness encountered in children's literature is part of the normal use of language, only a minor part that one responds to (as the reader) or actively uses (as the writer). Crystal [2002:395] further explains that "in everyday speech and writing, Deviance, it seems, is Normal. Strangeness is Familiarity. And Familiarity, as everyone knows, breeds content". If linguistic strangeness is normal and familiar, it does not exclude unintelligible speech such as baby-talk]):

A particularly striking instance (because it turns out to be so widespread, crosscultural, and international) is the speech of adults talking to babies, where the phonetic structure of words is radically altered, nonsense syllables are introduced, and bizarre (from the point of view of normal adult language) intonation and rhythm patterns used (Crystal [1990: 15]).

Though not intended as humour but as a loving and caring verbal interaction, nonsense is introduced to infants where intonation and rhythm take precedence over meaning. Since babies do not understand the "words" of language, they respond to its prosody. In children's literature, the deformation of language (deformation of the phonetic structure, added syllables and reduplication) is a familiar reminder of infant speech interaction.

According to Crystal [2002: 406], "any of the recognized domains of language structure and use can be manipulated in order to provide the input to a joke". He thus describes instances of graphological humour (e.g. spelling, punctuation, layout, typography), phonological humour (e.g. tongue twisters, spoonerisms, malapropisms), but also comic alphabets, morphological humour (e.g. playing with affixes, portmanteaux), lexical humour (e.g. pun), syntactic humour (e.g. Tom Swifties) (Crystal [2002: 406-411]). Crystal [2002: 409] also explains that "the vast majority of jokes have a fixed discourse structure" (e.g. What's the difference between an $X$ and a Y?), and that language variety is also a source of humour (e.g. speech idiosyncrasy, accents, vocal style). Finally, Crystal [2002: 411] points out that "it is not possible to use the written medium to capture the dynamics of joke-telling - especially the crucial role played by prosody, and by the interaction of face and tone of voice". 
Linguistic deviance can be regarded as linguistic strangeness; it can also be considered as a marginal use of language. Katz [2018: 141] provides the following explanation on wordplay:

Take, for instance, the sentence The cat is on the table. As such, nothing suggests that this is anything other than an ordinary utterance, with no ludic dimension. But it would be easy to take it and add a rhyme, thereby injecting a clear element of play and easy, too, to continue to a full-blown poem [...] Alternatively, one could play with The cat is on the table by highlighting that all the words but the last are monosyllabic (The cat is on the table; a ball lies in the gutter; no girl sings at John's party); or that the second word begins with the letter c (The cat is on the table; so are the cod, the cleat, the cereal, and the chasuble) or the sound [k] (The cat is on the table; so are the kit, the khat, the qanun, and the chemical) [...]; etc. etc. etc. What makes all of these cases of wordplay - and what makes puns, autograms, and games of Scrabble cases as well - is that each of them not only involves some degree of self-reflexivity, pointing in its very form to its status as language, but elevates form to the point of content and sometimes even beyond.

Playing with words, elevating them from and beyond the point of content or meaning, might prevent any possible resolution on the part of the receiver. Katz [2018: 141-142] analyses language as a ball and what is not language lies outside the ball:

Suppose we imagine language as a ball. Most linguists are interested principally in "core" phenomena, that is to say, in what lies at and near the center of the ball; a few, however, find it interesting to consider more "marginal" material, what in German are called Randphänomene, figuring that any good theory has to account for everything that counts as language, not just what is usual.

Katz [2018: 142] explains what is hard to consider as English:

To take an infamous example from Chomsky (1957: 15): while Colorless green ideas sleep furiously (sometimes called the "Chomsky sentence") is certainly a curious example of English, nowhere near the core from a semantic and pragmatic point of view, it is in fact - and undeniably - English; by contrast, its inverse, Furiously sleep ideas green colorless, though it contains the very same five words and thus appears to be language, is "word salad". In the second "sentence", the five words are given in an order that not only makes them (arguably) not an example of English but from some perspectives, including (arguably) the playful one, places their collocation outside the ball of language entirely.

Rather than stating that language only operates within defined norms, one can accept that bending the rules is still language. Katz [2018: 142] calls it "language on the verge". To study language on the verge is to analyse how far the linguistic medium can be bent and still be understood as language even if it denies pragmatic, morphophonetic and semantic standards.

Children's literature is full of verbal play. Playing on the verge of language, children's literature is not much concerned with spelling, grammar, syntax, morphology or meaning. Nonsensical formations are common in children's literature. There is no reason why authors of children's literature should not bamboozle with word norms. However, not all instances of language on the verge will be perceived by the reader as humorous, especially if the reader cannot resolve the incongruity.

Nonsense as a genre in children's literature is not exactly "word salad" but rather a partial semantic void in an utterance. For Lecercle [1994: 67], "semantic void is the locus either of no creativity or maximal creativity" allowing "an infinity of potential meaning". 
31 Lecercle [2017:3-4] considers that the "lack of meaning that obtrudes is no dissolution of language." On the contrary, for him, "the lack of meaning turns out to be a kind of excess; the floundering of any global meaning, or global structure, reveals a proliferation of partial meanings and structures, as if the failure of analysis did not put a stop to it but on the contrary prevented it from stopping." Lecercle [2017: 5-6] has his own terminology for what has been previously referred to as linguistic strangeness or language on the verge. He calls it "the remainder":

I shall no longer treat language as a scientific object, susceptible of a comprehensive description in terms of system and coherence, i.e. in terms of Saussure's concept of Langue. There is another side to language, one that escapes the linguist's attention, not because of his temporary failure or failings, but for necessary reasons. This dark side emerges in nonsensical and poetic texts, in the illuminations of mystics and the delirium of logophiliacs or mental patients. [...]. I have called it "the remainder".

Nonsense is characterised by "non-transparency of language" (Lecercle [1994:3]), which could be considered an obstacle to humour. How can the incongruity be resolved if nonsensical language lies beyond system and coherence?

In psychology, the perception of humour is analysed in two main categories of humour known as incongruity-resolution and nonsense humour. The difference between both types is explained by Hargrave et al. [2006] as follows:

It is well accepted that the humor comprehension processing involves incongruity detection and resolution and then induces a feeling of amusement. However, this three-stage model of humor processing does not apply to absurd humor (so-called nonsense humor). Absurd humor contains an unresolvable incongruity but can still induce a feeling of mirth.

One can thus consider that a young reader would feel amused reading a nonsensical utterance such as Dahl's "Gunghummers and bogs winkles!" without necessarily having to resolve its incongruity, i.e. without making much sense out of this sequence.

\section{Humorous schemes, tropes and collocations in children's literature}

Undeniably, pushing the boundaries of the linguistic medium is common in children's literature where authors are free to play with language by ignoring conventions. However, playing with language and humour are two distinct concepts. Bell [2016: 129] explains it as follows:

Current understandings of humour see it as a matter of juxtaposing incongruities and then (at least partially) resolving them, with the result being a feeling of mirth (for example Attardo \& Raskin, 1991; Oring, 2003; Suls, 1972). Language play, on the other hand, does not necessarily involve incongruities and their resolution, but might instead draw on and create linguistic patterns using, for instance, repetition, rhyming, and alliteration (for example Carter, 2004; Cook, 2000).

Language play is not necessarily incongruous and word creation (salience by novelty) is not necessarily playful, nor does humorous wordplay imply lexical creation. The data analysed in the present article is drawn from unattested word forms, thus it cannot detect, for instance, the satirical humour in Wilde. I cannot present an exhaustive description of humour in my corpus of children's literature. However, as Munat [2016: 101] states, humour is "often coterminous with lexical creativity". Thus, my data 
on creative wordplay presents adequate examples for an analysis of humour in children's literature.

Deviance in children's literature concerns all aspects of conventional language. Wordplay is not restricted to lexical deviance but can be achieved by departing from conventional grammar and syntax, orthography and phonology as well as altering established collocations. My selection of utterances linked to humour have been enhanced empirically from the initial database of unattested forms. I have chosen to describe them as schemes (figures of speech that deal with word order, syntax, letters and sound, rather than meaning) and tropes ("figures of speech which consist in the use of a word or phrase in a sense other than that which is proper to it" [OED3]). Deviance in meaning does not require altering the word form. The instances I describe were generally found in the co-text of unattested lexemes. For instance, Dahl's unattested "alive alive-o" led me to a paronomastic pun with muscles < mussels humorously associating the strength of giants with an Irish folk song6:

(2) Those giants is all at least fifty feet tall with huge muscles and cockles alive alive-o. (Dahl).

A few occasionalisms were also used in phrases ("frack to bunt") which led me to analyse the violation of strong collocations (salience by surprisal). For lack of finding an automatic way to extract them, I did a manual review of The BFG by Dahl and thus this type of salience is described without reviewing the whole corpus.

\subsection{Humorous schemes and tropes}

There are different ways of classifying deviant utterances considered as wordplay. Indeed, an author can play with any of the lexicogenic processes (see Poix [2019: 37-41]). Thus, we can consider morphosemantic wordplay (for instance playing with affixations as in un-birthday ${ }^{8}$ ), semantic wordplay (for instance the literalisation of a figurative meaning as in butteryfly ${ }^{9}$ ) and morphological wordplay (for any alteration of the signifier). In the present article, I have chosen to describe figures of speech rather than lexicogenic processes - encountered in my database of playful utterances.

To identify the processes encountered in my data, I used an online rhetoric lexicon, silva rhetoricae (The Forest of Rhetoric), and henceforth referred to as Silva.

According to Silva, four categories of change are identified:

Addition, subtraction, transposition, and substitution comprise the four categories of change. These are fundamental rhetorical strategies for the manipulation and variation of discourse across a vast array of linguistic levels: word forms, sentences, paragraphs, entire texts or speeches, etc.

These have been used as categories to identify changes in word forms considered to be vices; as generative strategies for invention; as stylistic possibilities for both tropes and schemes; as pedagogical methods for developing rhetorical flexibility (see copia and rhetorical exercises); and as methods of imitation by which one could transform a model into something different and original.

41 The analysis of my data shows that subtraction is mostly used to reflect orality. Addition and transposition are commonly used to create playful schemes, while substitution generates tropes. 


\subsubsection{Humorous schemes}

Different types of addition occur in wordplay: adding one or several phonemes or morphemes to existing words, or even inserting a word between parts of a compound or between syllables of a word. Dahl is the only author in my corpus to use the addition of phonemes (epenthesis ${ }^{10}$ ) as wordplay.

(3) Addition of a sound: fibb(l)ing, glamour(l)y, jump(s)y, shoot(l)ing, skidd(l)ing, sp(l)iffing, sp(l)ongy. ${ }^{11}$

In my data, the most commonly added phoneme in word deformation is /1/. Sometimes the lengthening resembles suffixation (e.g. "jumpsy"), however it is probably more likely a case of epenthesis.

(4) Addition of a syllable: bag(gle)pipes, grab(bl)es, jump(ell)ing, snor(tl)ing, swig(gle), swim(el)ing. ${ }^{12}$

In all of the above examples, the added syllable is /əl/, and it is also likely to bear a hypocoristic connotation. The addition of a syllable can also point towards another stem, as in the case of "jiggyraffes" < giraffes. It could be analysed as a blend [(JI)GGY $\mathrm{x}$ (GI)RAFFE], with a splinter (almost phonetically matching). Mirth is achieved when the deviance leads to several possible reinterpretations of the utterance. Here is another example:

(5) Twenty-four feet is puddlenuts in Giant Country. (Dahl).

In (5) "puddlenuts" < peanuts can also be analysed as a blend: [(P)UDDLE x (P)eaNUTS]

If the addition is placed at the end of the word it is termed paragoge ${ }^{13}$, while prothesis ${ }^{14}$ defines the initial addition. Tolkien uses paragoge with the addition of the phoneme /s/ at the end of words to describe the hissing speech of the character Gollum (e.g. eggses, eyeses). However, such deviance is not necessarily humorous. There are only two instances of prothesis in my data, both coined by Dahl: "(s)quarrelling" and "(gob)bit". The latter possibly reflects the addition of a vowel sound to ease the pronunciation of a velar followed by a bilabial in connected speech: "a nice long gobbit". Prothesis and epenthesis can be combined, as in "(s)crump(i)et". The resolution of the joke is generally given in the co-text:

(6) 'Oh, you poor little scrumpiet!' cried the BFG.

In (6) the cooccurrence poor little crumpet helps identify the deviant "scrumpiet" and thus the incongruity is easily resolved.

The insertion of phonemes can make the reading more complex (e.g. "rhino(sto)ss(t)erisses ${ }^{15}$ ") showing that idiosyncrasy can be achieved through the phonological complexity of the occasionalism. "Rhinostossterisses" becomes a playful tongue-twister.

A morpheme can also be playfully added to a lexeme:

(7) 'You is not fit to be a giant! You is a squinky little squiddler! You is a pibbling little pitsqueak! You is a... cream puffnut!' (Dahl).

In (7) the reference to cream puff is obvious. Therefore, the addition of nut in "cream puffnut" is not a case of nonsensical composition but the purely recreational 
unnecessary addition of a morpheme. There are two further examples by Dahl, "hippo(dumpling)s", "ear(wig)s".

The addition of a morpheme can be a case of tmesis"16: "scrumdiddlyumptious" < scrumptious, "skididdling" < skidding (Dahl). In both cases, the addition of the morpheme diddl(y) bears no semantic charge. ${ }^{17}$

Another case of tmesis by Dahl is more complex:

(8) If an animal is very fierce and you is putting it in a cage, it will make a tremendous rumpledumpus.

In (8), rumpus is split to insert *pledump or *umpled which do not exist. However, it is possible that *umpled is a clipped form of crumpled. In which case, it would be a case of telescoping two lexemes without the semantic charge of one of the constituents.

In the Rennie's dictionary we have the following information about "rumpledumpus":

RUMPLEDUMPUS noun RUMPLEDUMPUSES: a very noisy fuss or protest. To make rumpledumpus, Roald Dahl started with rumpus, which also means a noisy fuss, and made it twice as long and twice as funny by adding extra syllables. You can make other words this way, such as rumblegrumble, or even rummedybumble, for the noise your tummy makes when you are hungry.

This excerpt, aside providing the reader with a possible definition of "rumpledumpus", explains lexical wordplay, especially creating words which are twice as funny, being twice as long. The addition of sounds, morphemes or lexemes into existing words are definitely an opportunity for humour.

51 Transposition can also be a means to playful schemes. Rowling's aforementioned instance of mirror writing demonstrates the importance of the sequential order of letters and the segmentation of words in language. Transposition in a deviant utterance can be the result of an unconscious mistake, an encryption or a stylistic feature. A slip of the tongue generally refers to oral speech production, when someone mistakes one word for another. In literature, it can be found in dialogues:

(8) 'Your brain is full of rotten-wool.' 'You mean cotton-wool,' Sophie said. (Dahl)

When using stylistic transposition devices such as metathesis ${ }^{18}$ or spoonerism ${ }^{19}$, the author leaves the decryption of wordplay to the reader and may provide assistance in the co-text:

(9) Metathesis: Ah! And there's the cetemery" - cemetery, he must have meant. (Stevenson)

Metathesis coined by Dahl: bunderbluss < blunderbuss, knack jife < jackknife, porteedo < torpedo, prossefors < professors, rommytot < tommyrot, etc.

Spoonerism coined by Dahl: catasterous disastrophe < disastrous catastrophe, curdbloodling < blood-curdling, squeakpips < pipsqueaks, thirstbloody < bloodthirsty, jipping and skumping < jumping and skipping, snapperwhippers < whipper-snapper, Dahl's Chickens < Charles Dickens, etc.

Examples in (9) show that the transposition can divide one lexicalised complex lexeme into two (knack jife < jackknife). Alternatively, hyphenated compounds can be spelt as one (curdbloodling < blood-curdling, snapperwhippers < whipper-snapper). Deviance occurs at several levels (e.g. morphology and orthography). 


\subsubsection{Humorous tropes}

Of the rhetorical categories of change, substitution is mostly used for playful tropes. Three types of substitution have been identified: using the incongruity of homophones (antanaclasis ${ }^{20}$ ), quasi-homophones (paronomasia ${ }^{21}$ ), or associating two sets of meanings (simile) that seem incompatible.

With regards to antanaclasis and paronomasia, Lecercle [2017: 80] compares the two stylistic figures as follows:

The obstreperousness of the attempt is three-quarters of the fun. In a way, we can understand why distant paronomasia is preferable to the perfect variety, which rhetoricians call antanaclasis. The wilder the pun the better, because it does violence to language instead of meekly following its call. In antanaclasis, language speaks; the paths are well traced, the diverging meaning clearly in view. In paronomasia, it is I who speak. I make language do my bidding. I take an untrodden path, only faintly indicated by language - I force my way through words.

There are two types of antanaclasis. Firstly, the homophone can be repeated (antanaclasis in praesentia) as in the 1954 advertisement: "People on the go... go for Coke". Alternatively, there is one single occurrence and the homophone is inferred (antanaclasis in absentia):

(11) Oh, Queen! Oh, Monacher! Oh, Golden Sovereign! Oh, Ruler! Oh, Ruler of Straight Lines! Oh, Sultana! (Dahl).

In (11), the BFG addresses the Queen as "Ruler of Straight Lines", highlighting the misuse of ruler (without a capital letter) and the odd form of address. When the Queen is further addressed through antanaclasis in absentia as "Golden Sovereign", the adjective golden enables the reader to link the monarchical Sovereign with the gold sovereign coin.

In children's literature, illustrations can also be used to link the meaning of two homophones. This is achieved through the "patterning of the graphemic signifier" explained by Tsur [2010: 15-16] as follows:

There are many insightful discussions exploring the semantic interaction between the visual arrangement of such poems [picture poetry, anagrams] with their contents, syntactic structure, etc. The focus of my discussion will be different. I will attempt to account for the judgement of artificiality, with reference to a hierarchy of arbitrary signs: grapheme $\rightarrow$ phoneme $\rightarrow$ meaning $\rightarrow$ extralinguistic referent (each later item being the signified of the preceding one). Both picture poetry and certain sound effects [...] result from assigning two sign functions to one signifier on the graphemic and the phonemic levels, respectively.

Carroll uses a calligram to add a visual enhancement to wordplay. In Alice, a mouse is telling a long and sad tale which Alice mistakes for its tail:

(12) 'It IS a long tail, certainly,' said Alice, looking down with wonder at the Mouse's tail; 'but why do you call it sad?' And she kept on puzzling about it while the Mouse was speaking, so that her idea of the tale was something like this:-

The narrative that follows is written in the form of the appendage. 
Figure 1. Carroll, manuscript of Alice's Adventures in Wonderland, held at the British Library calligram ${ }^{22}$

Image 10037DF800000BC3000012F7E15A966E7E510CC6.emf

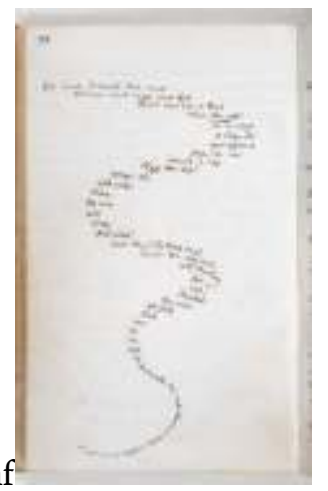

The antanaclasis used in Carroll's narrative illustrates an extreme case of the poetic function of a graphemic signifier.

Paronomasia - also called punning - is defined in Silva as "using words that sound alike but that differ in meaning". The same process can also be termed "malapropism", which is "the ludicrous misuse of words, especially in mistaking a word for another resembling it" (OED3). Malapropism generally points out an unconsciously inappropriate use of words, due to ignorance. The association of quasi-homophones is likely to lead to wordplay:

(13) 'Oh! you know me, do you?' cried the Artful, making a note of the statement. 'Wery good. That's a case of deformation of character, any way.' (Dickens).

Dickens is not the only author using paronomastic puns as in "deformation" < defamation. Carroll famously defines various subjects taught to the Mock Turtle:

(14) Reeling and Writhing > Reading and Writing / Ambition, Distraction, Uglification and Derision $>$ Addition, Subtraction, Multiplication and Division / Mystery and Seaography > History and Geography / Laughing and Grief > Latin and Greek / Drawling, Stretching and Fainting in coils > Drawing, Sketching and Painting in Oils.

Dahl also plays with puns: "cannybull" < cannibal and its derived form "cannybully", "human beans" < human beings which can lead to further wordplay:

(15) 'What is all you flushbunking rotsome half-baked beans doing in our country?'

Example (15) shows that multiple levels of wordplay are possible. Once the relation between humans and beans is established, and the reader knows that humans are food to giant there are limitless possible witty associations:

(16) 'The human bean,' the Giant went on, 'is coming in dillions of different flavours. For instance, human beans from Wales is tasting very whooshey of fish. There is something very fishy about Wales.' 'You means whales,' Sophie said. 'Wales is something quite different.' 'Wales is whales', the Giant said. 'Don't gobblefunk around with words. I will now give you another example. Human beans from Jersey has a most disgustable woolly tickle on the tongue,' the Giant said. 'Human beans from Jersey is tasting of cardigans.' 
In (16) Dahl demonstrates the incongruity of homophones with the antanaclases "Wales" < "whales" (in praesentia) and "Jersey" (in absentia). In the latter, the homophone is alluded to with the hyponym cardigan.

61 Commonly, language uses similes to describe words through comparison of their sets of meanings: "hard as a stone" (Barrie), "snorting like a steam-engine" (Carroll), "still as a mouse" (Dahl), "dry as a lime-basket" (Dickens), "dumb as a man" (Kipling), "straight as a bullet" (Lewis), "as sharp as a knife" (Pullman), "stiff as a board" (Rowling), "swift as a blow" (Stevenson), "black as a top-hat" (Tolkien), "monstrous as a madman's dream" (Wilde)... Similes can be metaphorical and sometimes they are lexicalised (e.g. "sharp as a knife" which is used by Barrie, Dahl and Pullman).

In CHILL, I identified similes where the comparison does not clarify the meaning but makes it opaque, for instance by using nonsensical association: "deaf as a dumpling", "happy as a hamburger" (Dahl). We have here a semantic shift, since a dumpling cannot be deaf nor a hamburger happy. The association only aims at creating an alliteration, giving precedence to sound over meaning.

Coinages are also used in similes. Dahl often compares an attested lexeme with an opaque occasionalism placed after the preposition as or like: "fast as a fizzlecrump", "full as a frothblower", "dotty as a dogswoggler", etc. When the occasionalism is opaque, its meaning is deduced by the associated lexeme. Hence, a fizzlecrump is something/ someone fast, a frothblower is something/someone full, and a dogswoggler is something/ someone dotty. When Dahl uses two occasionalisms in the comparison, the reader has to figure out at least one of the elements. For instance, "snuggy as a sniggler" can be understood if "snuggy" is perceived as a hypocoristic affixation of snug, making a "sniggler" something/someone snug. The nonsensical semantic shift can be analysed further. Dahl's above-mentioned examples are all alliterations, thus there is a sonorous playful function to these coinages.

\subsection{Humorous collocations}

Collocations are a continuum between cooccurrences and idioms described as follows by Manning \& Schütze [1999: 175]:

At one extreme of the spectrum we have usage notes in dictionaries that describe subtle differences in usage between near-synonyms like answer and reply (diplomatic answer vs. stinging reply). This type of collocation is important for generating text that sounds natural, but getting a collocation wrong here is less likely to lead to a fatal error. The other extreme are completely frozen expressions like proper names and idioms. Here there is just one way of saying things and any deviation will completely change the meaning of what is said.

Deviant collocations are necessarily incongruous and present an opportunity for wordplay. All cited examples described in this subsection were coined by Dahl. It appears, prima facie, that this type of deviance by surprisal is simply achieved by surprising the reader with an utterance which does not match the original expression stored in his/her mental lexicon. Indeed, the "accessibility condition" seems a prerequisite. Munat [2016: 102] explains it as follows:

[T] here is a vast area of research on creativity in fixed or frozen multiword strings, such as idioms, metaphors, proverbs, etc., generally referred to as 'phraseological expressions'. Kuiper (2007) instead uses the term 'phrasal lexicon', while van Lancker Sidtis and colleagues (2012: 88) have proposed the term 'formulemes', by 
which they mean formulaic expressions that have stereotyped form, conventionalised meanings, and a close connection with social variables. These properties are part of speaker competence, and the listener, in order to understand creative variations of formulemes, must be familiar with the base form - what Kuiper (2007: 96) calls the 'accessibility condition'. Without this knowledge, the play on words created by intentional deformation of the original expression would be totally lost.

For the child reader to have access to the original expression, one could consider that only strong collocations can be deformed - i.e. those with a high frequency. This is verified with the following example:

(17) "You is less or more right."

The above example is an anastrophe from the collocation "more or less". The frequency of the collocation in the British National Corpus is as follows:23

Table 1. Frequency in the BNC of "more or less"

\begin{tabular}{|l|l|l|}
\hline more or less & 2081 & AV0 CJC AV0 \\
\hline more or less & 211 & DT0 CJC AV0 \\
\hline more or less & 148 & DT0 CJC DT0 \\
\hline more or less & 71 & AV0 CJC DT0 \\
\hline
\end{tabular}

67 The parts of speech might not be easy to identify by tagging software, but there are over 2,500 occurrences of "more or less" in the BNC and none of "less or more". Since the collocation is well-established, changing the customary place of the consecutive word is wordplay. Otherwise, "less or more" would remain completely unnoticed.

There are enough instances of deviant collocations coined by Dahl to further analyse the types of deformation a phrase can undergo. Manning \& Schütze [1999: 172, 173] also provide the criteria that are prototypically used to identify collocations. Their first characteristic is non-modifiability: "many collocations cannot be freely modified with additional lexical material or through grammatical transformations." (Manning \& Schütze [1999:173]). The second characteristic is non-substitutability: "we cannot substitute near-synonyms for the components of a collocation." (Manning \& Schütze [1999: 172]). Thus, the rhetorical four categories of change can be used as strategies for wordplay. "Less or more" becomes a case of transposition. In fact, changing the customary place can have a tremendous impact on the meaning of the collocation:

(18) "Is it ever occurring to you that a human bean who is fifty is spending about twenty years sleeping fast?"

As a matter of fact, being "fast asleep" is quite distinct from "sleeping fast". A sensible meaning for "sleeping fast" is also hard to conceive. Transposition is not limited to words - spoonerism can also be found in collocations (frack to bunt < back to front). Ludicrous transposition can also be found in malapropism:

(19) You can go looking into every crook and nanny. (Dahl). 
For a child reader, the accessibility of "nook and cranny" is potentially not as easy as the words crook and nanny. Therefore, the deviant collocation is possibly nonsense humour.

There are several instances of substitution which are not limited to the near-synonyms mentioned by Manning \& Schütze. One of the constituents of the phrase can be replaced by a homophone (phew and far between, $<$ few and far between), a hypernym (born last week < born yesterday), a cohyponym (keep your skirt on < keep your shirt on), etc. The substitution can be more complex:

(20) "I has dillions of dreams on my shelfs, right or left?" [...] "Human beans is having their own music, right or left?"

In (20), the polysemy of the first constituent right is considered for choosing its other antonym.

The substitution can also be motivated by rhyme (once in a blue baboon < once in a blue moon). Part of another phrase can also be substituted:

\section{(21) "Are you sure you is not twiddling my leg?"}

This is a playful mixture between "pulling my leg" and "twiddling my thumb". Spontaneously, the reader understands the meaning of "pulling my leg", probably due to the fact that "twiddling one's thumb" is reflexive and so "you" cannot be its agent. Substituting twiddling for pulling is wordplay and remains accessible. It would not have been the case if Dahl had used ?are you sure you is not pulling my thumb.

71 Addition, as a stylistic strategy for deviance is also possible in collocations (hold your horsefeathers < hold your horses). Hold your horses is an attested phrase, old-fashioned and informal, "used to tell someone to stop and consider carefully their decision or opinion about something." ${ }^{24}$ It is nonsensical to use any compound made with the name of equid. In fact, horsefeathers is a slang term meaning "nonsense", so the pun from Dahl links two figurative expressions into one strange utterance.

Addition can also be combined with transposition (every what way and which < every which way).

72 No cases of subtraction have been identified, which does not imply that this type of deviance is not possible. It rather emphasises the fact that the incongruity of wordplay is more commonly achieved by complexity than concision. It is interesting to note that violated phrases retain one of the characteristics of collocations: they are mostly noncompositional. "The meaning of a collocation is not a straightforward composition of the meanings of its parts" (Manning \& Schütze [1999: 172]). Violating a collocation is not annihilating it but recreating it.

\section{Conclusion}

Deviance in children's literature is a creative form of expressive language that an extravagant writer can use to amuse the reader. Such a foregrounding of the linguistic medium can be the result of several types of salience, through lexical creativity (salience by novelty), by drawing the reader's attention (salience for its attentiongetting potential), or by flawing predictive models (salience by surprisal). 
Deviance is part of the normal use of language, even if it's only marginal. Indeed, language is not restricted to defined norms and bending the rules of the linguistic system, even defying the semantic standard, is common in children's literature.

The mere act of playing with words does not necessarily lead to humour. Two parameters are considered for the perception of humour, incongruity and resolution. This is not systematic in wordplay. As such, rhyming may entertain a child but is not considered humorous. There are two types of humour: incongruity-resolution and nonsense humour, thus nonsensical wordplay is still droll.

6 Deviant utterances with a humorous effect can be the result of stylistic strategies, using the categories of change (addition, transposition and substitution, mainly) to create playful schemes (e.g. epenthesis, tmesis) and tropes (e.g. paronomasia, antanaclasis). Such stylistic features also apply to the violation of collocations.

The foregrounding of linguistic deviance forces the reader to linger over the reading in an attempt to decipher the hidden meaning of the text. There is a sense of achievement in the resolution of incongruity. A young reader might not resolve all humorous utterances and instead enjoy wordplay as nonsense humour. However, at an older age, the incongruity may be resolved. Deviance in children's literature is possibly one of the reasons why adult readers still enjoy reading children's books. Unveiling unresolved wordplay sheds a new light on the book itself.

\section{BIBLIOGRAPHY}

Primary sources (corpus CHILL_EN: CHILdren's Literature)

BARRIE James Matthew, 1911, Peter and Wendy, Project Gutenberg: available at https:// www.gutenberg.org/ebooks/26654 (accessed 5 February 2016).

CARROLL Lewis, 1865, Alice's Adventures in Wonderland, Project Gutenberg: available at https:// www.gutenberg.org/ebooks/11 (accessed 17 November 2015).

DAHL Roald, 2007 (1982), The BFG, Puffin.

DICKENS Charles, 1837, Oliver Twist, Project Gutenberg: available at https://www.gutenberg.org/ ebooks/730 (accessed 17 February. 2016).

KIPLING Rudyard, 1894, The Jungle Book, Project Gutenberg: available at https:// www.gutenberg.org/ebooks/236 (accessed 15 March 2016).

LEWIS Clive Staples, 1950, The Lion, the Witch and the Wardrobe, available at http:// www.ereading.club/bookreader.php/71014/Lewis__The_Lion\%2C_the_Witch_and_the_Wardrobe.html (accessed 22 March 2016). PulLmAn Philip, 1995, Northern Lights: His Dark Materials 1, Amazon RHCP Digital, available at https://www.amazon.fr/Northern-Lights-Dark-Materials-Englishebook/dp/B00SSJYFAQ/ (accessed 3 August 2016). 
RowLING J.K., 1997, Harry Potter and the Philosopher's Stone, Amazon Pottermore, available at https://www.amazon.fr/Harry-Potter-Philosophers-Stone-Rowling-ebook/dp/B019PIOJYU/ (accessed 26 July 2016).

STEVENSON Robert Louis, 1882, Treasure Island, Project Gutenberg, available at https:// www.gutenberg.org/ebooks/120 (accessed 17 February 2016).

ToLKIEN John Ronald Reuel, 1937, The Hobbit, available at https://ia800302.us.archive.org//items/ TheHobbitCollectionJRRTolkien/The\%20Hobbit\%20Collection\%20-\%20JRR\%20Tolkien.pdf (accessed 5 February 2016).

WILDE Oscar, 1887, The Canterville Ghost, Project Gutenberg, available at http:// www.gutenberg.org/ebooks/14522 (accessed 9 July 2016).

\section{References}

ATTARDO Salvatore, 2018, "Universals in Puns and Humorous Wordplay", in WINTER-Froemel Esme \& THALER Verena (Eds.), Cultures and Traditions of Wordplay, Berlin and Boston: De Gruyter, 89-110. BELL Nancy D., 2016, "Humour and language play", in JonEs Rodney H. (Ed.), The Routledge Handbook of Language and Creativity, London and New York: Routledge, 129-142.

CRYSTAL David, 2002 (1995), The Cambridge Encyclopedia of the English Language, Cambridge: Cambridge University Press.

CRYSTAL David, 1990, “Linguistic Strangeness", in BRIDGES Margaret (Ed.), On Strangeness, Swiss Papers in English Language and Literature (SPELL) 5, Tübingen: Gunter Narr, 13-24.

DRESSLER Wolfgang U., 1994. "Word-formation: Poetic License”, in ASHER RONALD E. \& SIMPSON J. M. Y. (Eds.), The Encyclopedia of Language and Linguistics, Oxford: Pergamon press, 5028-5030.

HARgRAVe Petrina A., SCOTT Kate M. \& McDowall John, 2006, "To resolve or not to resolve: Past trauma and secondary traumatic stress in volunteer crisis workers", Journal of Trauma Practice 5, n², London: Taylor \& Francis, 37-55, also available at 10.1300/J189v05n02_03 (consulted $21 / 11 / 2020)$.

KATZ Joshua T., 2018, “Exercises in wile”, in WiNTER-Froemel Esme \& THALER Verena (Eds.), Cultures and Traditions of Wordplay, Berlin and Boston: De Gruyter, 137-164.

KELLER Rudi, 2014, Sprachwandel, Von der unsichtbaren Hand in der Sprache, $4^{\text {th }}$ edition, Tübingen: Francke.

LECERCLE Jean-Jacques, 2017 (1990), The Violence of Language, London: Routledge.

MANNING Christopher D. \& SCHÜTZE Hinrich, 1999, Foundations of Statistical Natural Language Processing, Cambridge, Massachusetts: MIT Press.

MUNAT Judith, 2016, “Lexical creativity”, in JoNES Rodney H. (Ed.), The Routledge Handbook of Language and Creativity, London and New York: Routledge, 92-106.

OED3, Oxford English Dictionary, available at https://www-oed-com.bibelec.univlyon2.fr/.

PHRASES IN ENGLISH, interface to access the British National Corpus, available at http:// phrasesinenglish.org/ (consulted 21/11/2020).

POIX cécile, 2018, “Neology in children's literature: A typology of occasionalisms", in JAMET Denis \& TERRY Adeline (Eds.), Lexical and semantic neology in English, Lexis 12, available at http:// journals.openedition.org/lexis/2111. 
POIX cécile, 2019, "Les jeux de mots dans la littérature pour la jeunesse : typologie des procédés de (ré)création lexicale et stratégies de traduction des créations ex nihilo", in BRISSET Frédérique \& Coussy Audrey et al. (Eds.), Du jeu dans la langue Traduire le jeu de mots, Villeneuve d'Ascq: Presses Universitaires du Septentrion, 35-51.

RENNIE Susan (Ed.), 2016, Oxford Roald Dahl Dictionary, Oxford: Oxford University Press.

SCHMID Hans-Jörg, 2020, The Dynamics of the Linguistic System: Usage, Conventionalization, and Entrenchment, Oxford: Oxford University Press.

SILVA RHETORICAE, 2007, provided by BURTON Gideon O., Brigham Young University, available at http://rhetoric.byu.edu/ (consulted 21/11/2020).

TSUR Reuven, 2010, "The poetic function and aesthetic qualities: cognitive poetics and the Jakobsonian model", Acta Linguistica Hafniensia 42, 2-19.

\section{NOTES}

1. In 2016, to conduct a corpus-driven study on neology, I compiled a corpus of children's books (entitled CHILL: CHIldren's Literature). The compilation was based on the following principles: (i) the chosen titles are a reasonable representation of books which are or were recommended for children; (ii) the corpus is not limited to one genre and does not privilege nonsense or fantasy authors; (iii) the corpus is multilingual (German, English, French and Italian) and aligned, thus the availability of translated texts had to be considered. The present article only analyses part of this corpus, CHILL_EN, where English is the source language. This study does not account for the impact of any sub-genre (e.g. fantasy, nonsense, tale, etc.) on deviance and wordplay.

2. The selected exclusion list includes all inflected forms of British English spelling. It is available at http://www.mieliestronk.com/wordlist.html (accessed 4 April 2018).

3. If a potential neologism was listed in the OED3 with a sole example from the author and fiction I was referring to, I kept it in my data. For instance, merry-go-rounder is attested with a sole example by Dickens and was thus considered neological.

4. For instance: Gadsby by Ernest Vincent Wright [1939] written without the letter e, or the work of the French literary movement Oulipo in the twentieth century.

5. Rowling's "Erised stra ehru oyt ube cafru oyt on wohsi" should be read as "I show not your face but your heart's desire"

6. The song Molly Malone: "In Dublin's fair city, / where the girls are so pretty / I first set my eyes on sweet Molly Malone / As she wheeled her wheelbarrow / through the streets broad and narrow / Crying, 'cockles and mussels alive, alive, oh!".

7. Coined by Dahl. See Section 3.2.

8. Coined by Carroll.

9. As Dressler [1994: 5029] states, "poets often remotivate words, that is restore the original transparent meaning. This is sometimes called poetic etymology". For instance, according to Etymonline, the etymology of butterfly is from "Old English buttorfleoge, evidently butter (n.) + fly (n.), but of obscure signification." It gives poetic licence for Dahl to coin butteryfly. The adjunction of the suffix $-y$ remotivates the compound butterfly.

10. 'Epenthesis: from Gk. epi, 'in addition,' and thesis, 'placing'. The addition of a letter, sound, or syllable to the middle of a word. [...] Epenthesis is sometimes employed in order to accommodate meter in verse; sometimes, to facilitate easier articulation of a word's sound. It can, of course, be accidental, and a vice of speech." (Silva).

11. Coined by Dahl.

12. Coined by Dahl. 
13. "Paragoge: from para 'beyond' and goge 'carrying'. The addition of a letter or syllable to the end of a word." (Silva).

14. "Prothesis: Also sp. prosthesis. The addition of a letter or syllable to the beginning of a word." (Silva).

15. Coined by Dahl.

16. "Also spelt timesis. Interjecting a word or phrase between parts of a compound word or between syllables of a word." (Silva).

17. In "scrumdiddlyumptious", there is also a repetition of -um after the additional morpheme.

18. Metathesis is defined in Silva as "the transposition of letters within a word".

19. Like metathesis, spoonerism is "an accidental transposition of the initial sounds, or other parts, of two or more words" (OED3).

20. Silva defines antanaclasis as "the repetition of a word or phrase whose meaning changes in the second instance). This definition can be extended to the repetition of homonyms (homophones and homographs).

21. "Paronomasia: Using words that sound alike but that differ in meaning (punning)" (Silva).

22. https://commons.wikimedia.org/wiki/File:Alice\%27s_Adventures_Under_Ground__Lewis_Carroll_-_British_Library_Add_MS_46700_f15v.jpg

The text differs in the illustration from Carroll's manuscript. In the printed edition, the text in the calligram is as follows: "Fury said to a mouse, That he met in the house, 'Let us both go to law: I will prosecute YOU. - Come, I'll take no denial; We must have a trial: For really this morning I've nothing to do.' Said the mouse to the cur, 'Such a trial, dear Sir, With no jury or judge, would be wasting our breath.' 'I'll be judge, I'll be jury,' Said cunning old Fury: 'I'll try the whole cause, and condemn you to death."

23. N-gram advanced search by .Phrases in English" accessible through http:// phrasesinenglish.org/explore.html (verified 28 April 2019).

24. The Oxford Advanced Learner's Dictionary of Current English, third edition.

\section{ABSTRACTS}

Idiosyncrasy in children's books is nothing peculiar. Authors often bend linguistic norms to amuse the reader. This article reviews deviance as a form of creativity leading to humour. Various approaches exist to describe incongruous language, ranging from normal strangeness to nonsense. Humour is considered in incongruity-resolution and in nonsense. The article describes deviant playful utterances found in children's books as rhetorical strategies for schemes and tropes. It also analyses the violation of collocations.

L'emploi dans les livres pour enfants de mots insolites ou singuliers n'a rien d'étrange. Les auteurs contournent les règles pour amuser le lecteur. Cet article examine la déviance lexicale comme une forme de créativité dont la fonction est l'humour. L'incongruité du langage peut être analysée selon des conceptions diverses, allant d'une étrangeté linguistique considérée comme normale jusqu'au non-sens. L'humour s'explique dans la résolution de l'incongruité comme dans l'incohérence humoristique (nonsense humour). Dans cet article, des énoncés ludiques extraits de livres pour enfant sont analysés selon des figures de styles appartenant aux schèmes et aux tropes. Il est également question du détournement des collocations. 
INDEX

Mots-clés: déviance, créativité lexicale, jeu de mots, saillance, humour

Keywords: deviance, lexical creativity, wordplay, salience, humour, collocation

\section{AUTHOR}

\section{CÉCILE POIX}

Université Lumière Lyon 2, France

C.Poix@univ-lyon2.fr 